\title{
ANALYSIS OF THE ORGANIZATION OF NURSING CARE PROVIDED FOR DISABLED CHILDREN IN SPECIAL EDUCATION INSTITUTIONS IN NORTH- WEST POLAND
}

\author{
Katarzyna Gawłowska-Lichota, Agnieszka Wróbel, Jacek Brodowski, Beata Karakiewicz \\ Laboratory of Family Nursing, Pomeranian Medical University, Szczecin, Poland
}

\begin{abstract}
SUMMARY
Introduction: It often happens that handicapped children and teenagers need to be taught in special educational centres. One of the specialists working in a special school should be a nurse having appropriate professional and methodical skills.

Material and methods: The research involved nurses employed in 36 special education institutions in 2006/2007 in the area of North-West Poland. The organization of work was analysed on the basis of specially constructed questionnaires.

Results: The average working time of nurses employed in special education institutions was 16 hours and 12 minutes per week. In the group of nurses examined, $69 \%$ persons have completed qualifications and $5 \%$ specialty courses. Nurses cooperate mainly with speech therapists, educationalists, psychologists, rehabilitators, specialists in surdo-pedagogy and oligophreno-pedagogy. However, they attended meetings with parents very occasionally (8\%) and rarely participated in staff meetings (8\%). Besides, $29 \%$ of participants met with parents exclusively in case of emergency.

Conclusions: Nurses' working time in special education institutions according to the norms or work organization. Not all nurses working with disabled pupils have the required qualifications such as the completed specialty or qualification courses. Nurses working in special education do not fully use the possibility of cooperation with the families of disabled pupils and specialists in the therapeutic team.
\end{abstract}

Key words: disabled children, special educational needs, special education, nursing care, equalization of opportunities

Address for correspondence: K. Gawłowska-Lichota, Laboratory of Family Nursing, Pomeranian Medical University, Szczecin, Poland. E-mail: kasia.gaw@wp.pl

\section{INTRODUCTION}

In accordance with legal guidelines, disabled children and adolescents in Poland are obliged to attend a school. It gives an opportunity to initiate an educational-didactic process which should stimulate every child to develop their skills in different areas depending on their condition. It should be possible then, to have a choice of the course of education and the type of a school. As it often happens, handicapped children and teenagers need to be taught with regard to their specific educational needs (1). This type of teaching may take place in public schools, integrated schools or departments, special schools or departments, and in special educational centres. The main purpose of special schools and rehabilitative-educational centres is to realize rehabilitativeeducational classes in the framework of preschool and school education, one-year preparation for school-learning and vocational education. However, it may be associated with the prolonged time of education, and thus preschool education can last up to the 10th year of life, learning in the primary school up to the 21st year of life and in the high school up to the 24th year of life.

According to many authors, in case of disabled children, the best learning place is an integrated school. A stay in such an institution positively affects their development and creates the possibility of their full participation in a peer group $(2,3)$. This is associated with social integration of handicapped persons and also with a decrease of negative consequences of such equality of rights. This aim can be achieved by means of the so-called integration system (4). And yet, this system is not perfect. At first, the biggest problem of integrated schools was a deficiency of well-prepared teaching staff and lack of architectural solutions on the school premises (5). Currently, the school system for disabled children includes providing appropriate equipment and facilities as well as preparation of teaching staff (6). Another aforesaid option that has been used so far is a stay in special schools for disabled children and teenagers. These institutions offer rehabilitative and educational classes assuming educational programme, and the form of classes is adjusted to the type of pupils' disability e.g. deafness and milder hearing impairments or blindness and partial loss of vision. Institutions conducting classes include among others special educational centres, rehabilitative-educational centres, special vocational schools and other special schools.

The above mentioned institutions should provide their tutees with proper sanitary, social and educational conditions (4). In other words, they should secure human resources and housing conditions which guarantee achievement of intended goals (6). One of the specialists working in a special school should be a nurse. The law regulates the norms of employment and education of nursing staff working in an educational environment. According to the decree concerning the extent and organization of preventive health care for children and teenagers, nurses, who provide services in 
didactic educational institutions, should complete specialty or qualification courses in the field of nursing in the teaching and educational environment (7).

In special schools for children and teenagers, who are physically fit but suffer from slight mental handicap, have auditory or visual impairments of different degree, or are chronically ill, it is recommended that a full-time nurse should take care of 150 pupils. In schools for children with slight mental handicap and physical disability, or physically fit but with moderate mental disability, a full-time nurse should look after 80 pupils. Whereas in institutions for students with physical and moderate or severe mental handicap, a full-time nurse should preferably watch over 30 pupils. Nevertheless, it should be remembered that a number of pupils per a full-time nurse should be established individually with regard to school specificity (8). Nurses providing services in special education institutions should cooperate with physicians and other specialists being the members of the therapeutic team. The composition of the therapeutic team depends on the type and specificity of a school (9). The standards also define tasks and expectations for nurses working in special education institutions. An important aspect is their individual work with disabled pupils as well as acting as a part of the therapeutic team. Hence, a nurse should cooperate with the whole school and local community for these pupils (15). Nursing work includes not only medical care, but also recognizing pupils' school environment and possible health risks, as well as assuring pupils' safety on the school premises.

Another issue is nurses' cooperation with parents or legal guardians of disabled children. Its basic aim is to find out how much parents and legal guardians know about their children's development and health state, to explain them why systematic control and observation by specialists is necessary, and to emphasize the importance of regular drug administration. It is equally important to clarify the purpose of rehabilitative and therapeutic care provided for children. Thus, constant contact between nurses and parents of disabled pupils should be a basic element of their cooperation (10).

\section{MATERIAL AND METHODS}

The study was conducted in the area of North-West Poland in the school year 2006/2007.

A research tool was a questionnaire based on an annual report on the tasks performed within the framework of preventive care provided for school children and teenagers as well as data passed to the Central Statistics Office ( $\mathrm{MZ}-06$ ) by Westpomeranian Centre of Health Organization and Promotion. The questionnaire included questions about educational background of people providing preventive care services for pupils, their working hours per week, a number of pupils in a school, cooperation with parents and specialists employed in an institution.

The questionnaire was sent to 40 special education institutions. It was completed by 38 nurses employed in 36 special education institutions.

The results obtained were subjected to statistical analysis and shown as the pie charts.

\section{RESULTS}

Based on the data made available by Westpomeranian Centre of Health Organization and Promotion, an observation was made that the student population in North-West Poland decreased in $2005 / 2006$ and 2006/2007 from 278,028 to 260,017. The abovementioned data also suggest that a number of disabled pupils reduced from 5,316 in the school year 2005/2006 to 5,109 next year.

Analysis concerned institutions where nursing services were provided. The results are shown in Fig. 1.

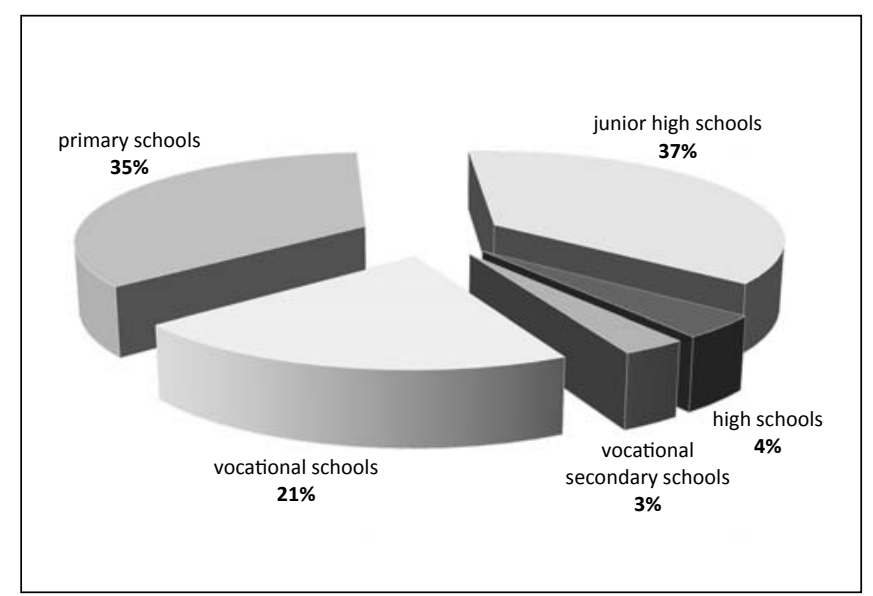

Fig. 1. Analysis concerned institutions where nursing services were provided.

In $37 \%$ of cases they were junior high schools, $35 \%$ primary schools, $21 \%$ vocational schools, $4 \%$ high schools and $3 \%$ vocational secondary schools.

As it follows from analysis of our research, at least one nurse was employed in each of the above-mentioned places. Additionally, every nurse working in a particular institution took care of almost 89 pupils with the Certificates of Medical Disability on average. The organization of care for disabled students is not merely referred to the cooperation with specialists and well-educated staff; another important element is working hours in particular institutions. The Mother and Child Institute clearly defines the norms of employment in educational institutions - 30-150 pupils per a full-time nurse depending on the school type, while it should be remembered that a full-time nurse works 7 hours and 35 minutes per day, i.e. 37 hours and 45 minutes per week. And yet, as it follows from analysis of questions about working hours in special education institutions, nurses work on average 16 hours and 12 minutes per week.

The organization of care for pupils is also associated with precisely specified requirements concerning educational background of nursing staff. The results are shown in Fig. 2.

The results show that in the surveyed group, $67 \%$ of nurses have completed qualification and $9 \%$ specialty courses in the field of nursing in the teaching and educational environment; as many as $25 \%$ of the surveyed have finished neither qualification nor specialty courses so they have not met the requirements concerning qualifications necessary to work in the teaching and educational environment. In the surveyed group, there were also nurses with the title of Master of Nursing (3\%), but in accordance with the 


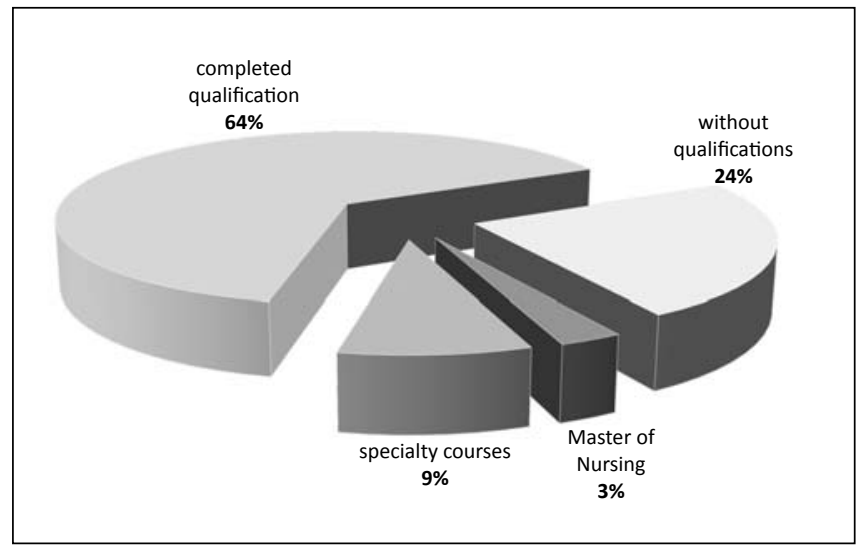

Fig. 2. Analysis of education of nurses surveyed.

decree, the title of Master of Nursing does not set its owner free from the duty to complete a qualification or specialty course in the required field.

The way of organizing nursing care for disabled pupils should be affected by interdisciplinary attitude to every student and their problems, and above all by effective cooperation with specialists employed on the school premises (Fig. 3).

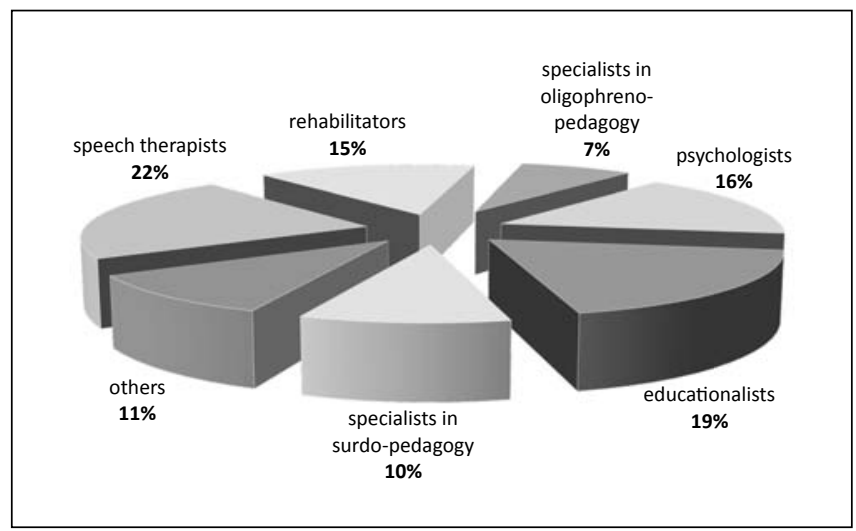

Fig. 3. Analysis in cooperation with specialists.

Specialists with whom nurses usually cooperate on the school premises include: speech therapists (in over $22 \%$ of cases), educationalists (18.7\% of cases), psychologists (16.4\%), rehabilitators (14.6\%), specialists in surdo-pedagogy (9.9\%) and specialists in oligophreno-pedagogy (7.6\%).

According to system assumptions, tight collaboration with families is essential to nursing care for pupils. The extent of cooperation between nurses and pupils' families is shown in Fig. 4.

The main persons to facilitate information between parents and specialists are nurses and form tutors (the form tutor is the person who contacts a parent if there is a problem at school). Unfortunately, analysis of our research revealed that nurses attended meetings with parents very occasionally (merely $8 \%$ of the surveyed). Only $7 \%$ of the surveyed nurses made an attempt to collect information in the family environment of handicapped children, and 8\% participated in staff meetings. Furthermore, $29 \%$ of the interviewed nurses met with parents exclusively in case of emergency.

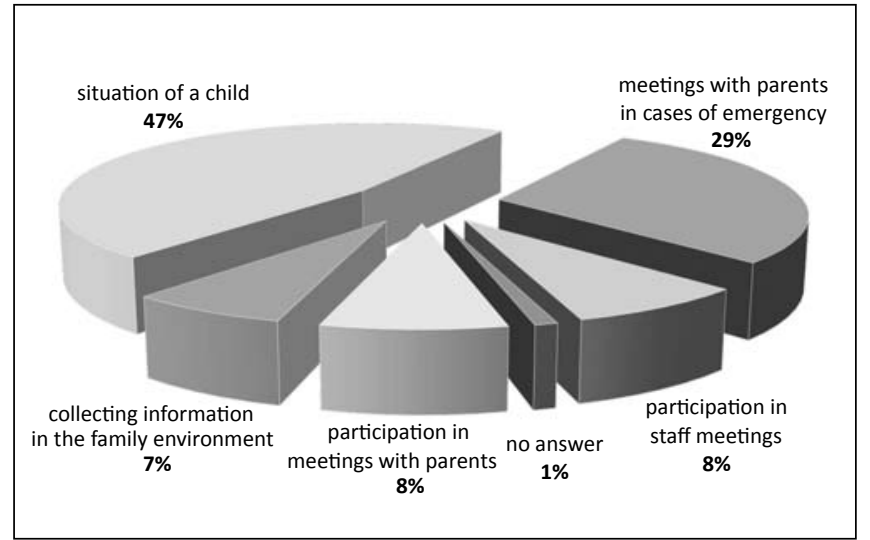

Fig. 4. Analysis in cooperation with parents.

\section{DISCUSSION}

Irrespective of the level and kind of limitations caused by disability, it is a reason for a number of difficulties in social functioning (10). Disability is treated in Poland as a huge public health problem. It looks similar in other European Union countries. Żółtowska claims that handicapped persons represent about $10 \%$ of the European Union society which means that in the Union countries there are about 37 million people with disabilities (11).

What is more, it is observed that the percentage of disabled individuals in the society constantly increases. According to Węgrzyn the number of disabled people in 2002 was $14,3 \%$ of the country's community. Also this author noticed high growth dynamics of disability in children aged up to 15 (12).

The results of our research, based on the data from 2005/2006 and 2006/2007 made available by the Central Statistics Office, do not reflect the above mentioned upward tendency and suggest fixed number of handicapped pupils in North-West Poland.

In accordance with the "Standard Rules on the Equalization of Opportunities for Persons with Disabilities" adopted at the session of the United Nations General Assembly in December 1993, disabled persons have the same rights and obligations as others (13). One of the tasks of the state policy is an integration of disabled individuals into the society, so that they could fully participate in social life. This goal is realized by means of such actions as creating a system of medical, social and occupational rehabilitation on one hand and, on the other, modifying physical and social environment through, among others, removing architectural obstacles and creating or adjusting schools and working places to the needs of disabled persons (6). All these actions give handicapped people a chance to prove themselves, stimulate them to competition and teach them independence, whereas healthy individuals learn to help others, to tolerate those who are different and to show compassion for the problems of other people $(2,3)$.

This idea should be realized, among others, in integrated schools and special education centres. According to an Order of Ministry of National Education from 4 October 1993, children and teenagers enrolled in special education should be provided with well-prepared teaching staff and other specialists being the members of the interdisciplinary therapeutic team. In accordance with the organizational assumptions of care provided for pupils, 
nurses bear the burden of health and preventive care on the school premises. Woynarowska believes that school nurses enjoy increasing prestige in the school community which is the result of their professional competence and raising qualifications as well as their great involvement and openness in relations with parents and other persons taking care of disabled students (14).

As it was already mentioned, an important factor deciding about the quality of nursing care in didactic educational institutions is the educational background of nursing staff. This is related to the necessity of having extensive knowledge of paediatrics, school medicine and health promotion as well as raising the level of awareness concerning cooperation with institutions and non-governmental organizations. Our results, however, do not confirm this tendency among nurses. Analysis of the data obtained revealed that not all school nurses employed in the institutions examined had the required qualifications, because the title of Master of Nursing does not entitle them to work in didactic educational institutions. The Order precisely defines the qualifications required to work as a nurse in the teaching and educational environment (7).

Oblacińska implies that the role of a nurse in a school is not restricted to the realization of preventive tasks, but it also involves solving current health problems of tutees and close cooperation with parents and specialists (15). It was found that nurses employed in the institutions examined were only slightly engaged in the collaboration with parents and specialists working on the school premises. Further analysis shows that the cooperation with parents was often limited to contacts in case of emergency.

The organization of nursing care was also analysed with reference to weekly working time of nurses employed in special education institutions. Describing the required standards of qualifications and norms of employment of a nurse and a matron, Jodkowska specifies the norms of a nurse's working hours in educational institutions (16). Following the above standards, nurses' working time should be 688 hours and 25 minutes. Our results suggest that nurses work shorter, namely 526 hours and 25 minutes.

Summing up, it was observed that the nursing staff providing services on the premises of the institutions examined is numerous enough. And yet, nurses are not professionally involved in the collaboration with parents of pupils and they do not work as long hours as they should to comply with accepted norms. It shows that there is the necessity of greater involvement and raising the level of awareness of nurses working on the school premises.

\section{CONCLUSIONS}

1. Nurses' working hours in special education institutions are insufficient according to the norms of work organization.

2. Not all nurses working with disabled pupils have the required qualifications such as the completed specialty or qualification courses.
3. Nurses working in special education do not fully use the possibility of cooperation with families and specialists in the therapeutic team. It most probably results from the fact that the standards of employment and professional qualifications are not applied as they should be.

\section{REFERENCES}

1. Reform of the system of education of children with special educational requirements. Warsaw: Ministry of National Education; 1998. (In Polish.)

2. Bogucka J. School principal: responsible integration requires that. Dyrektor Szkoły. 1997;(2):12-4. (In Polish.)

3. Libiszowka-Żółtkowska M. Attitudes towards the disabled demonstrated by primary school teachers. In: Apolinarska M, Dryżałowska G, Kleszczewska-Pyra E, Libiszowska-Żółtowska M. Łuczak-Okrasińska $\mathrm{B}$, Stojanwoska E, editors. Integration of handicapped children in the kindergarten and school. Warsaw: IFiS PAN; 1994. (In Polish.)

4. Kościelak R. Psychosocial functioning of mentally disabled people. Warsaw: Wyd. Szkolne I Pedagogiczne; 1996. (In Polish.)

5. Fenczyn J, Wyczesany J, editors. Education and integration of handicapped people: materials of the First European Congress „The Disabled Closer to Europe”. Kraków: Ostoja; 1994. (In Polish.)

6. According to an Order of the Ministry of National Education from 4th October 1993, children and teenagers enrolled in special education should be provided with a well-prepared teaching staff and other specialists being the members of the interdisciplinary therapeutic team. Warsaw: Ministry of Health; 1993. (In Polish.)

7. The Resolution by the Minister of Health of December 22nd 2004 on the range and organization of preventive health care for children and teenagers. Warsaw: Ministry of Health; 2004. (In Polish.)

8. The Resolution by the Minister of Health of June 16th 2003 on the requirements that the provincial health plans should meet and the range of data necessary to prepare such plans. Warsaw: Ministry of Health; 2003. (In Polish.)

9. Wojciechowska A, Wiśniewska A, Jodkowska M, Oblacińska A, Pułtorak M, Wrocławska M. Incompetent pupils. Magazyn Pielęgniarki i Położnej. 2002;6(2):22-3. (In Polish.)

10. Daunt P. Education, rehabilitation and integration of handicapped people in the European Union. Skolepsykologi. 1988;23:45. (In Norwegian.)

11. Żółtowska T. Alignment of chance of social person with inetellectual incompetence. Conditionality and areas. Szczecin: Oficyna in Plus; 2004. (In Polish.)

12. Wegrzyn G. The disabled on the labour market. In: Niebrój L, Kosińska M, editors. Unemployment and health care. Katowice: Wyd. ŚAM; 2004. (In Polish.)

13. Karwat ID. Epidemiology of incompetence. Selected medical problems and with incomplete proficiency social persons. In: Jabłoński L, editor. Epidemiology for students. Lublin: Wyd. Folium; 1999. (In Polish.)

14. Wojnarowska B, editor. Health and school. Warsaw: PZWL; 2000. (In Polish.)

15. Oblacińska A. Health problems of disabled pupils. Magazyn Pielęgniarki i Położnej. 2002;6(4):17-8. (In Polish.)

16. Jodkowska M. Standards and methodology of the works of school nurses and matrons. In: Oblacińska A, Ostręga W, editors. Handbook for school nurses and matrons employed in schools of different types. Warsaw: IMiDz; 2003. (In Polish.)

Received July 23, 2008 Accepted in revised form November 21, 2008 